\title{
The development of wind power in China, Europe and the USA: how have policies and innovation system activities co-evolved?
}

\author{
Will McDowall $^{\mathrm{a}}$, Paul Ekins ${ }^{\mathrm{a}}$, Slavo Radoševićb and Le-yin Zhang ${ }^{\mathrm{c}}$ \\ ${ }^{a}$ UCL Energy Institute, University College London, 14 Upper Woburn Place, London, UK; ${ }^{b}$ School of Slavonic and East \\ European Studies, University College London, 16 Taviton Street, London, UK; ${ }^{c}$ Development Planning Unit, University \\ College London, 34 Tavistock Square, London, UK
}

\begin{abstract}
This paper takes an innovation system approach to analysing the development of wind energy in three jurisdictions: the EU, USA and China. The paper builds on and extends previous innovation system studies on wind in two ways. First, it focuses on the interactions over time between policy and innovation system dynamics, in order to highlight lessons for low-carbon policymaking. Second, it extends the analysis from the formative and growth phases of the innovation system to the globalisation and transfer phase, in which mature technologies are transferred to new markets. The conclusions are: first, policies should go beyond 'market pull' and 'technology push' and should take into account the institutional frameworks through which they are delivered; second, policies have been more successful where they prioritised long-term learning-oriented deployment rather than short-term efficiency; third, system failures exist at the transfer stage of development as well as during formative and growth phases.
\end{abstract}

Keywords: technological innovation system; wind power; innovation policy

\section{Introduction}

The development and deployment of new, low-carbon technologies is an essential part of efforts to mitigate climate change. However, historical trends are clear: energy technologies do not tend to emerge and diffuse quickly because of a wide range of barriers to invention, development and diffusion (Fouquet 2010; Grübler, Nakicenovic, and Victor 1999; Kramer and Haigh 2009). Policymakers need to identify ways in which the process can be accelerated.

Classic economic approaches to low-carbon innovation policy (e.g. Popp 2010; Stern 2007) tend to focus on correcting two key market failures (the carbon externality; and the non-appropriability of R\&D knowledge). We find this approach too narrow as it ignores a variety of institutional and system failures. Instead, we build on the technology innovation system perspective developed by Bergek et al. (2008) and Hekkert et al. (2007). Using a case study on wind energy in the USA, UK,

\footnotetext{
*Corresponding author. Email: w.mcdowall@ucl.ac.uk
} 
Germany and China, we build on and extend that framework to highlight the roles of policy and global technology transfer. Our reasons for this, and an overview of the relevant literature, are set out in the next section. The third section gives a very brief historical overview of the development of wind power, before the detailed activity analysis of the penultimate section. The general results and conclusions arising from this analysis are reported in the concluding section. Further details of the case study countries described in the paper can be found in the Supplementary Online Material.

\section{Approaches to innovation policy}

\section{Correction of market failures}

Many studies of low-carbon technology policy adopt an economic approach that focuses on market-pull and technology-push as the forces shaping innovation, and that emphasises market failure as the rationale for policy and the guide to shaping it. This literature is well summarised by Popp (2010), who describes two market failures affecting low-carbon innovation: first, the difficulty of appropriating the value of knowledge, leading to socially sub-optimal private sector investments in $\mathrm{R} \& \mathrm{D}$ (requiring policy to supplement 'technology-push'); and second, the fact that the social costs of greenhouse gas emissions are not reflected in the costs of emitting activities, leading to socially sub-optimal investment in mitigation and hence limited 'market-pull' for low carbon technologies (Stern 2007).

Policies that create a market for low-carbon technologies are not only important for providing an incentive to invent and develop new technologies - they are also critical in enabling the widespread deployment of new technologies. We can therefore understand market incentives for low-carbon technologies as having a dual policy role: a direct role in reducing emissions, and an innovation role because they foster learning-by-doing and provide market incentives for future innovation.

The market failure approach suggests that if entrepreneurs are able to fully appropriate their returns from innovation, and if market prices reflect costs of emitting carbon, then the workings of the market would result in the emergence of a low-carbon economy, as long as policymakers can remove barriers to the effective functioning of markets. Yet the case studies presented here show that, while the correction of market failures is important, the emergence of low-carbon industries entails the operation of much more complex socio-economic and governance processes.

\section{The innovation system approach}

It is increasingly recognised that approaches based on correcting market failures, while useful in justifying policy intervention, fail to provide policymakers with adequate guidance about how support for R\&D should be organised, or how market-pull policies should be structured. Innovation is better viewed as the outcome of system interactions, involving 'the network of institutions in public and private sectors whose activities and interactions initiate, import, modify and diffuse new technologies' (Freeman 1987). This perspective argues that low-carbon industrial development may be obstructed by system failures (Woolthuis, Lankhuizen, and Gilsing 2005), and narrowly defined market failure is an inadequate framework for informing innovation policy.

A system failure results from conflicts, inconsistencies or lack of coordination between a range of mechanisms that shape technical progress (Andersson 1998; Peneder 2008). Various authors have produced taxonomies of system failure (e.g. Edquist 2001; Hennessy, Roosen, and Jensen 2003; Woolthuis et al. 2005), and these highlight the diverse ways in which context can dominate economic incentives for innovation. Issues associated with infrastructure, lock-in, institutions, knowledge-flows, trust and capabilities are particularly prominent. 
The 'innovation systems' approach has system failure as its underlying rationale. There is a variety of innovation system concepts (Coenen and Díaz López 2010). The two most relevant here are the 'technological innovation system' concept (Bergek et al. 2008; Hekkert et al. 2007; Jacobsson and Johnson 2000), which describes the way in which technologies are developed by and within an innovation system; and the 'socio-technical system' approach (Geels 2002, 2004), which addresses major shifts in socio-technical arrangements. Both concepts emphasise that there are durable structures beyond price differences that prevent rapid change in sociotechnical systems, including physical infrastructures, institutional set-ups, expectations, routines and entrenched interests.

The technological innovation system (TIS) concept proposed by Jacobsson and Johnson (2000) is directly appropriate for thinking through the dynamics of an emerging industry, such as the wind power industry. It proposes that, in order to be successful, a new radical innovation must be fostered within an innovation system that successfully performs a number of critical functions, or activities:

(1) Generation and diffusion of new knowledge

(2) Entrepreneurial experimentation

(3) Guidance of the search

(4) Market formation

(5) Acquisition of legitimacy/overcoming resistance to change.

(6) Mobilisation of financing and resources

Different authors have adopted different versions of this typology of activities. We adopt that of Bergek et al. (2008), noting that they effectively treat a further activity 'development of positive externalities' as a descriptor of feed-back processes that arise where these six core activities are functioning effectively, and we therefore do not consider this an independent activity in the innovation system.

The TIS perspective highlights two stages in the development of the innovation system.

(1) Formative stage. During this period there may be no consensus on a dominant design, and the network of actors involved in developing the technology is largely informal and diffuse. The focus in this stage is on further development and experimentation rather than rapid deployment. The most critical policy instruments during this stage relate to the way in which research, development and deployment (RD\&D) support is organised.

(2) Growth and development stage. Once a dominant design has been identified, and cumulative installed capacity starts to grow, the innovation system becomes more oriented towards growth. The most critical policy instruments during this stage appear to be those focused on enabling the establishment of a self-sustaining market and industry.

The strength of the TIS approach is that it provides a detailed structure for understanding the interplay between policies and cultural, technical and economic developments. The innovation system approach is conceptually fully consistent with the evolutionary theory of technology policy, the key features of which are probably best articulated in Metcalfe $(1994,1995)$ and are: focus of policy on variety and selection, and on diffusion as well as on generation of knowledge; adaptive policy making; the importance of the wider institutional context; and the facilitation of the self-organisation of the innovation system. 


\section{Approach of this paper}

Wind energy has been previously studied using a TIS perspective. Indeed, the technological innovation system concept was first developed through studies on renewable energy technologies, including wind (Jacobsson and Johnson 2000). Previous studies have compared the wind innovation system in different European countries. We build on that earlier work, by extending comparison beyond Europe to the USA and an emerging power, China. Furthermore, we expand the analytic frameworks used by previous authors in two key ways:

(1) First, we adapt the methodological frameworks suggested by (Bergek et al. 2008) and (Hekkert et al. 2007) to focus on the on-going interactions between the innovation system and policymakers, in order to highlight the ways in which policies have addressed or exacerbated potential innovation system weaknesses. To do this, we have mapped policy events (e.g. introduction of new policy instruments) in each country, the background that enabled those policy events to take place, and the impacts that each policy event had on the dynamics of the innovation system. Drawing on quantitative and qualitative primary data on innovation system indicators, and on the substantial existing literature on the wind innovation system, we have constructed detailed policy and innovation system chronologies for each of the country studies.

(2) Second, we extend the innovation system analysis to a third phase of the innovation journey. As with previous analyses, we recognise a formative phase, and a subsequent growth phase. In this analysis, we build on these to explore a third, transfer phase. This phase focuses analysis on the processes by which countries absorb and deploy low-carbon technologies that were developed elsewhere. This process of technology transfer across borders has not previously been a focus of studies using the TIS approach, but is clearly critical if low-carbon technologies are to play a meaningful role in global decarbonisation.

Following a brief historical overview of wind power, this paper summarises our policy and innovation system chronologies by reporting on the development of each of the innovation system activities over time, highlighting in particular the indicators of innovation system activity. Detailed innovation system chronologies can be found in the Supplementary Online Material.

\section{Wind power case study: brief historical overview}

\section{The pre-history of modern wind (up to 1974)}

The early development of wind power was gradual, involving roles for niche markets and entrepreneurial experimentation. Wind electric systems had been built before 1900, the largest of which was the Smith-Putnam turbine built in Vermont, at over $1 \mathrm{MW}$. However, the costs and physical challenges of building turbines on this scale ensured that the design remained an experiment. During the 1920s and 1930s, small electric turbines became widespread until the electric grid rendered them obsolete (Taylor et al. 2006). This early experience of electric wind power was important, both in the US wind industry and in Denmark, since in both countries researchers and enthusiasts continued to dabble in wind power during the 1950s and 1960s. 


\section{The formative phase: 1974-1989}

The energy crises of the 1970s led to a burst of R\&D activity in Europe and the USA on energy technologies, including wind. R\&D funding from government enabled the generation of a variety of designs of turbine, drawing on a range of existing knowledge stocks and existing industries (aerospace, power electronics, agricultural machinery, shipbuilding). Enthusiasts and entrepreneurs developed small turbines, and government-funded testing facilities provided certification and monitoring. Small early markets flourished in Denmark, and in the early 1980s a wind 'boom' took off in the USA, in response to generous tax incentives. These initial markets enabled learning and skills development, and while the boom in the USA was followed by a bust, Denmark saw the continued development of wind throughout the 1980s.

\section{The growth phase: 1990-1998}

By the beginning of the 1990s, following Chernobyl and the acid rain crisis, interest in wind energy had resurfaced. Wind energy technologies had been proven in service and several governments created market deployment incentives. Policy in the UK focused heavily on competition and cost reduction, which prevented the immature industry from gaining strength and experience. Policies were effective in Germany, Denmark and Spain, which all saw steady growth in wind energy thanks to policy supports that exposed investors to little risk. Along with experience, technologies improved, costs fell and the industry developed a political voice that could lobby for further support. Innovative activity as measured by patents actually fell during this period, as companies focused on growth and developed practical experience, skills and know-how.

\section{Maturity and transfer phase: 1999-2010}

By 1999 success in initial markets (Germany, Spain and Denmark) had demonstrated the potential of wind as a real low-carbon option. This encouraged the entry of large, well established firms from the engineering (e.g. Siemens) and energy sectors (e.g. Enron), which further entrenched the legitimacy of wind. Industrial competitiveness emerged as a policy consideration as the global market for wind power looked set to expand. Political targets for wind energy became widespread and increasingly ambitious. Later in the period technology transfer to China - first via joint ventures and development funding, later via the establishment of domestic manufacturers and protectionist market supports, has enabled further growth in global wind deployments. The maturity and transfer phase has seen a renewed burst of innovative activity, as firms have focused on improving the technologies, reducing costs, and expanding offshore.

\section{Activities of the global wind innovation system: comparative analysis of indicators over time}

\section{Knowledge development and diffusion}

Knowledge development includes both explicit and tacit knowledge, but data are available only on explicit knowledge through patents and publications. Engineering know-how and design capabilities are equally important but much more difficult to assess. Indeed, knowledge accumulation in the wind power sector represents a 'bricolage' of R\&D-based activities and learning-by-doing (Harborne and Hendry 2009). 
Patents are one possible indicator of the development of knowledge in wind energy, although they are well known to be only an approximate indicator of innovation. Patents differ significantly in value; companies adopt alternative strategies to protecting knowledge; and so on. While patents do not provide a full picture, they do provide some insight into overall trends in wind power innovation, and into the differences between nations' innovative activities. Figure 1 shows the overall global trends in patenting in wind energy technologies between 1978 and 2005, using PCT patents. ${ }^{1}$

Wind energy patents went through a period of growth during the formative phase, when early turbine designs were becoming established. Patenting rates dropped during the early expansion phase, as R\&D budgets declined. Patenting rates have increased very strongly since 2000 , as the wind energy industry has gone through rapid expansion into maturity.

Figure 2 shows the early lead of the USA in wind energy patenting and the rise of Germany during the 1990s. Denmark held less than 5\% of global patents prior to 1997, by which time Danish firms and Danish technology had become market leaders globally, and has never held more than $10 \%$ of wind energy patents. Historical accounts of the wind sector suggest that Denmark relied less on major R\&D projects for knowledge development, and more on learning-by-doing, particularly in the early days of the wind sector (Garud and Karnøe 2003), with firms perhaps relying less on patenting to protect their technological expertise.

An alternative measure of knowledge development is the number of papers published in the academic literature. This is complicated by the linguistic diversity of the academic literature. Nevertheless, a chart of papers published in the English-language literature (see Figure 3) shows a similar trend to overall patenting rates and closely follows overall global R\&D funding for wind.

Knowledge diffusion occurs through networks of actors, via conferences, trade journals (such as Wind Engineering, founded in 1977, and Windpower Monthly, founded in 1985) and so on. A more formalised mechanism for knowledge diffusion is through licensing of intellectual property, which provides an indicator of the diffusion of innovations into new firms and markets. As the wind innovation system has matured, and developed into a global industry, this route of knowledge diffusion has become important. Licensing has been the main mechanism of technology transfer to China (Lewis 2007). Around US\$450m flowed from China to European and American firms

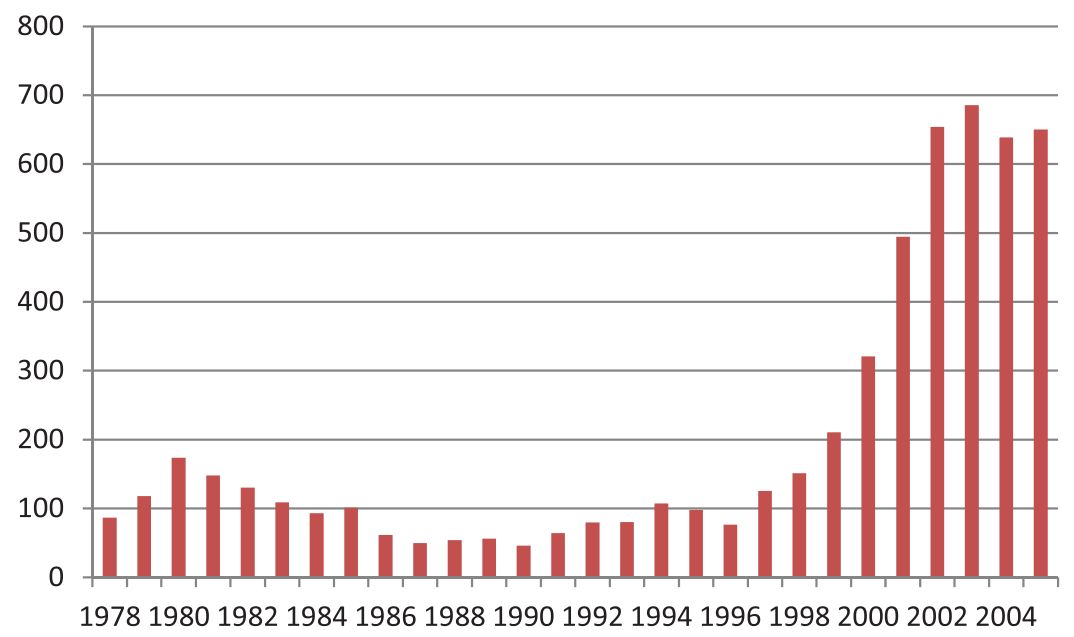

Figure 1. Patent applications for wind energy technologies (WIPO 2010). 


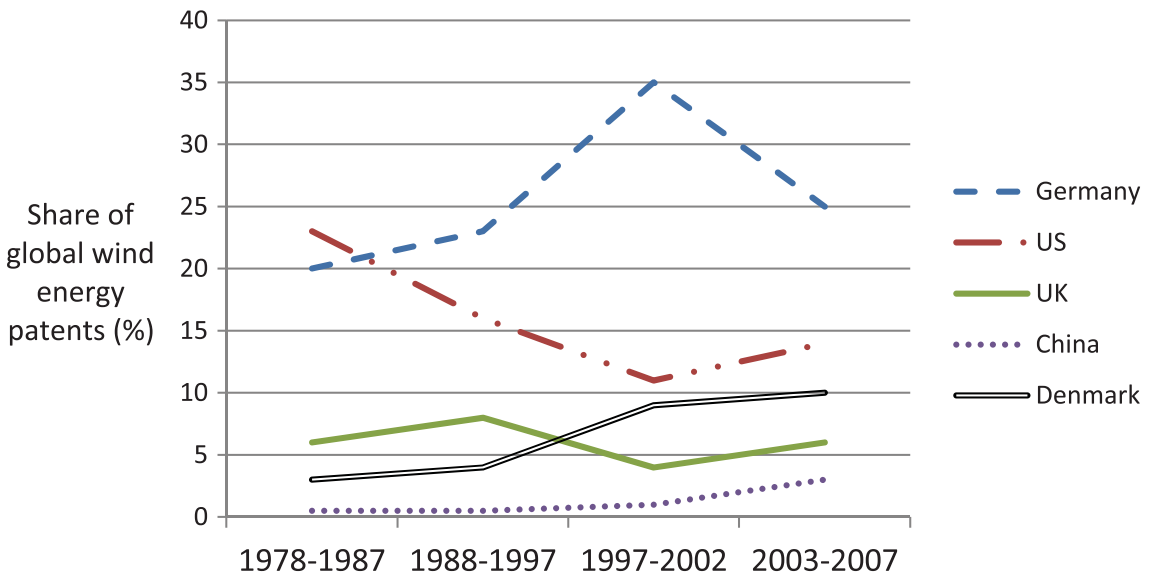

Figure 2. Countries' shares of wind energy patents (WIPO 2011).

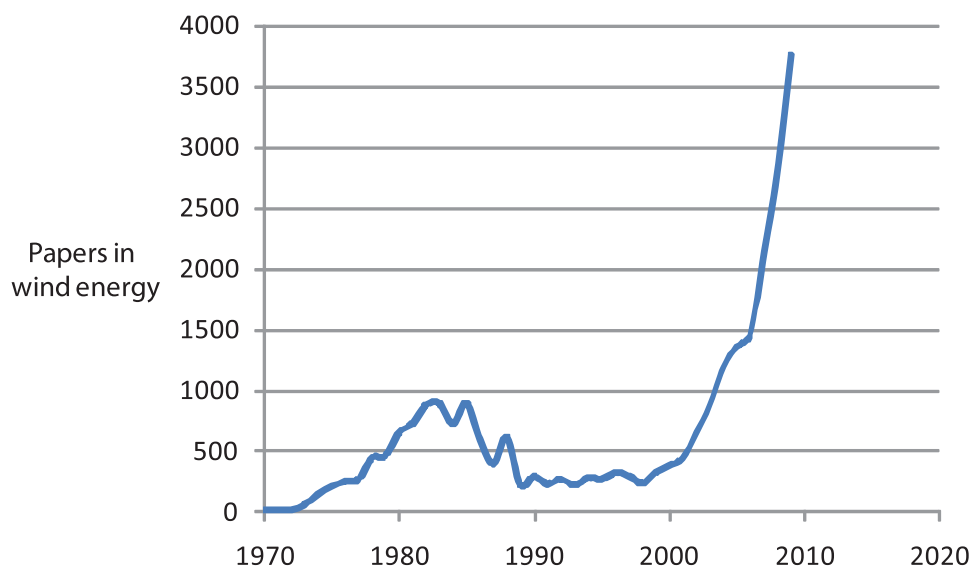

Figure 3. Papers published on wind energy in the English-language academic literature, based on results from searches of the SCOPUS database for 'wind energy', 'wind turbine' and 'wind power'.

in 2009 alone, in the form of patent royalties, manufacturing licences and technical consulting ( $\mathrm{Li}$, Shi, and Gao 2010), suggesting that this system of knowledge diffusion is functioning effectively. However, leading western firms have been reluctant to license their latest designs, because of competition concerns, and as a result Chinese firms have relied on either out-of-date designs or those developed by second-tier western firms (Lewis and Wiser 2007).

\section{Associated policy instruments in each jurisdiction}

Public R\&D and demonstration project funding was of critical importance in enabling knowledge development in the wind innovation system during the formative phase. Data on public R\&D funding are available from the International Energy Agency (IEA) for Germany, the UK and USA (see Figure 4). The chart illustrates the major increase in R\&D that took place in many countries following the oil shocks of the 1970s. Funding declined in the early 1980s when the oil price stabilised and then fell, in the USA under Reagan during the 1980s, and in the UK 


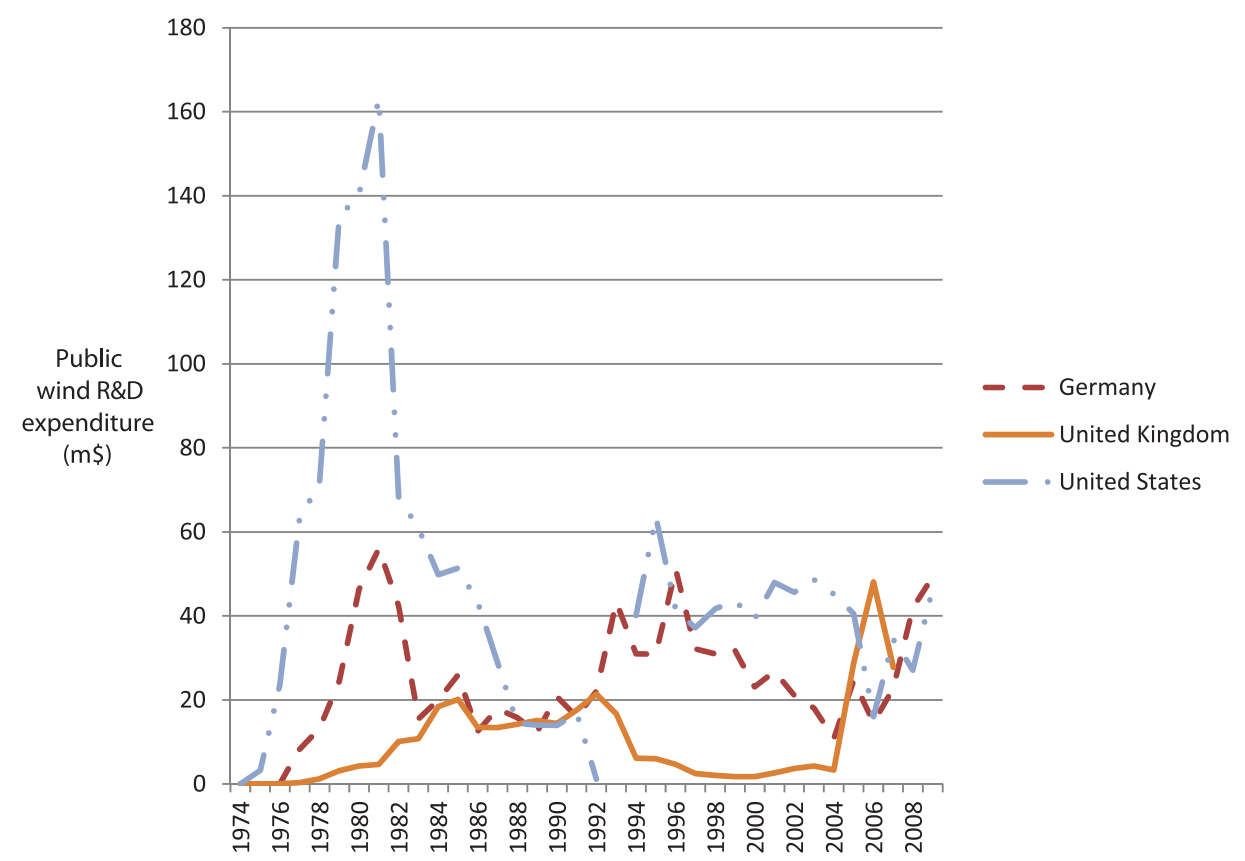

Figure 4. Public R\&D spending on wind in Germany, the USA and UK. Data for China is not publicly available (IEA 2011).

after liberalisation in the 1990s. In Germany public funding for R\&D peaked in the mid-1990s, declined as the industry became commercially established, taking off again as global competition in the industry became more pronounced. The UK is shown to be a late-comer in terms of public R\&D into wind energy.

Patenting rates appear to follow global R\&D funding for wind, with a peak in the late 1970s in both funding and patenting, followed by a downturn from the mid-1980s, and increased public $R \& D$ funding and patenting since 2000 . Nemet (2009), using a quantitative analysis of wind energy patents and US R\&D funding, argues that this relationship implies technology push policies (i.e. $\mathrm{R} \& \mathrm{D}$ funding) were more successful at promoting innovation than those creating early markets. Similarly, Klaassen et al. (2005) have assessed the importance of R\&D funding in the development of wind power patents, estimating that learning-by-searching (i.e. $R \& D$ ) was more important than learning-by-doing in the development of wind technologies. These studies suggest that R\&D funding has been the driving policy instrument in the development of knowledge for wind energy.

However, more detailed historical accounts of the wind innovation system question this result, arguably revealing the dangers of relying on patents as proxies for knowledge development. Such accounts (e.g. Garud and Karnøe 2003) make clear that in spite of the fall in patenting rates, major learning and technological development still took place during the late 1980s and the 1990s in the form of engineering 'know-how'. In particular, scale-up of turbines was a key technological advance during these years, from an average of less than $100 \mathrm{~kW}$ before 1990 , to over $600 \mathrm{~kW}$ in 1998 (Gipe 1994; IEA 2001). In addition to scale-up, many other key technological developments took place in the late 1980s, such as the development of variable-speed turbine technology. Furthermore, UNEP, EPO, and ICSTD (2010) find that wind energy patents are less strongly correlated with R\&D funding than are most other kinds of clean energy patent, while Lee, Iliev, 
and Preston (2010) find that only a small number of patents are obviously the direct result of public sector research.

Detailed accounts of the sector provide insight into the ways in which the structure of $R \& D$ policy contributed to wind innovation success. Jacobsson and Johnson (2000) emphasise that early R\&D projects in Sweden, the Netherlands and Germany focused on developing large-scale, multi-MW turbines. These projects were largely unsuccessful (Heymann 1998), whereas projects in Denmark focusing on learning and scaling-up smaller designs that showed better performance were more successful. Similarly, German programmes supporting experimental deployment (in particular the $100 \mathrm{MW}$ programme) were more successful in fostering the development of viable turbine designs. In other words, pre-conceived ideas about the appropriate direction of search (see the following subsection), imposed by those funding R\&D programs, led to slower development than those in Denmark and later in Germany. Similarly, in a comparison of the USA and Denmark, Garud and Karnøe (2003) argued that the US R\&D programme was premised on the ability of scientists and engineers to find a 'breakthrough' that would enable large-scale turbines to be deployed, whereas the Danish programme relied on close networking between users, test centres and engineers, using low-tech designs that worked and could slowly be improved and scaled up. This suggests that those countries that emphasised learning-by-doing rather than learningby-researching were more successful in terms of diffusion and the acquisition of technological capabilities.

The story of wind does not imply that low-tech, incremental approaches are a certain route to R\&D success (indeed, it has been argued that a similar bottom-up approach to wind innovation in Japan failed to develop a strong domestic industry (Matsuoka 2005)) but rather that knowledge development is dependent on the other activities of a well-functioning innovation system, such as entrepreneurial experimentation, appropriate guidance of the search, networking and so on. R\&D programmes are therefore likely to be more effective when they are established within a broader supportive policy framework that addresses these other issues. R\&D funding cannot be seen as supplying technological knowledge, but as enabling it to be produced within a broader system.

In China, a latecomer to wind energy, policy focused on first catching up and then competing with the dominance of established firms. Three policy areas are relevant: (1) funding R\&D both in universities and in emerging wind turbine manufacturers, principally through the 863 and National Key Technologies Programmes (MOST 2011); (2) pursuing technology transfer mechanisms, such as support for joint ventures (the 'Ride the Wind' programme) and the Clean Development Mechanism, and (3) increasingly requiring domestically owned IP in determining project eligibility in concession bidding (Lewis 2007). Chinese firms have relied heavily on licensing foreign designs, but have now developed considerable intellectual property of their own, in large part in response to this high degree of policy support.

\section{Entrepreneurial experimentation}

Various accounts (Garud and Karnøe 2003; Jacobsson and Johnson 2000; Jacobsson and Lauber 2006) indicate that the early formative phase involved considerable entrepreneurial experimentation with a wide range of turbine designs and configurations, with eventual commercial convergence in the mid-1980s on the broad dominant design (three-blade, horizontal axis - though it should be noted that there have been continued debates about the details of this configuration, in terms of pitch control and gear systems in particular). This occurred particularly in the USA and Denmark, but also in the Netherlands, Sweden and Germany. 
Entrepreneurial experimentation strongly contributed to development of the wind innovation system, one indication of which was the introduction of new technologies, with a trend for increasing turbine size over time.

Figure 5 shows the size increases in average installed turbines over time. The largest turbines, particularly those deployed offshore, are considerably larger than these average figures. Offshore $5 \mathrm{MW}$ and $6 \mathrm{MW}$ turbines have been installed in UK, Germany and Belgium, and in 2010 Vestas commercially launched a $7 \mathrm{MW}$ turbine for offshore projects.

In terms of new firms, there is clear evidence of considerable entrepreneurial experimentation in most of the countries studied. Actors have continued to enter the market in recent years, both in terms of new start-up companies (e.g. BARD and MultiBrid in Germany, Clipper in the USA, all since 2005) and entry into the wind industry of large, established energy firms, such as General Electric (2003) and Siemens (2004). The development of a wind market in China has enabled a rapid proliferation of entrepreneurial wind firms.

\section{Associated policy events in each jurisdiction}

Several authors have highlighted policies that enabled entrepreneurial experimentation in wind. For example, Germany's emphasis on funding a diversity of designs and firms in early deployment programmes has been seen as important in the development of Germany's successful wind industry (Jacobsson and Lauber 2006). In contrast, early deployment funding in the UK, through the NonFossil Fuel Obligation (NFFO), was focused on deploying least-cost technologies, a move that inhibited diversity and learning and acted as a barrier to entrepreneurial new entrants (Mitchell and Connor 2004). Similarly, the California wind boom in the 1980s enabled, through generous capital supports, a great deal of entrepreneurial experimentation. However, this came without sufficient incentive to improve performance and reduce costs, and without requirements for installations to participate in early monitoring, reducing the contribution of this boom to knowledge development and legitimacy.

In later periods, UK policy supports for the development of offshore wind, through capital grants and through the Carbon Trust Offshore Wind Accelerator, appear to have enabled greater entrepreneurial experimentation in the formative phase of the offshore wind industry. Similarly,

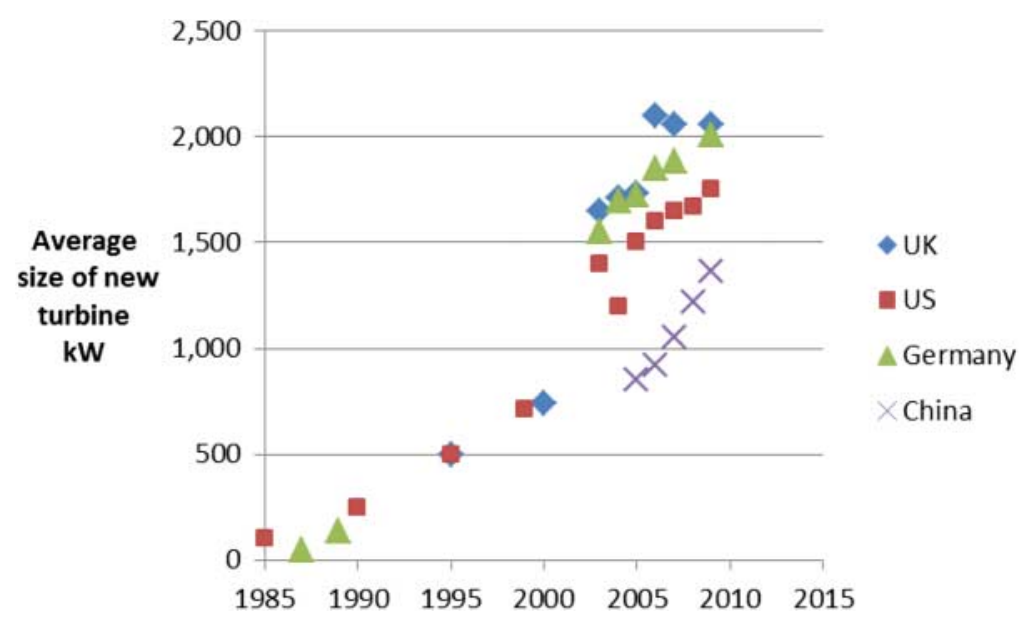

Figure 5. Average size of turbines installed in that year in the UK, the USA, Germany and China. Data compiled from IEA Wind Annual Reports, Jacobsson and Johnson (2000) and Li et al. (2010). 
Chinese policy supports have explicitly focused on enabling entrepreneurialism and market entry from domestic players in the industry, largely through 'domestic content' requirements in various support mechanisms.

China did not experiment with wind until the end of the formative phase, with initial installations resulting from bilateral development projects beginning in the late 1980s, and little progress until the mid-1990s. Since 2005, the use of renewable portfolio standards applied to major electricity suppliers, combined with domestic content requirements in concession projects, has created a guaranteed market for Chinese turbine manufacturers. As a result, the market has seen an entrepreneurial explosion - but with comparatively little technological experimentation. Most turbine firms have simply licensed existing European designs.

Perhaps unsurprisingly, the conclusion is that policy instruments that provide support for early markets and enable diverse new entrants are good ways of stimulating entrepreneurial experimentation. This echoes policy recommendations from the broader transition management literature, which highlights the importance of enabling the development of 'protected spaces' or 'niches' in which a new industry and technology can co-evolve (Kemp, Schot, and Hoogma 1998). In contrast, policy instruments focused too early on deploying least-cost technology prevent new players from entering the market and stifle experiments with technological novelty (e.g. the NFFO in the UK; Mitchell and Connor 2004).

\section{Guidance of the search}

The literature on socio-technical change emphasises that in mature innovation systems, the direction of search is relatively well defined, with actors within the system following similar technological trajectories, and with clear incentives for new actors to join the system (Bergek et al. 2008). In the case of wind, clarity in the direction of search within the innovation system has become well established with the growth of the industry.

It is in the formative stages of an innovation system that this function is most challenging, since by definition this stage is characterised by higher uncertainty, higher investment risks and a lack of alignment among actors. For new technologies competing within the power sector there is a sense in which the search is framed by clear market demands, as users of electricity already exist and their demands are well articulated. At this basic level, then, the guidance of search for low-carbon electricity technologies is well defined.

Two challenges remain in establishing a clear direction of search. First, the emerging system needs to develop a credible vision of the future of wind energy as part of the power sector, to provide incentives for new actors to join the system. This requires the building of confidence in the technology and confidence in the future of policies to reduce emissions. Second, in the emerging innovation system, the network of actors needs to articulate and diffuse information about specific technical needs. This is achieved through both technical activities that assess and test different options and by social processes through which knowledge is exchanged, needs articulated and priorities agreed.

Expectations about the future of an energy technology are not simple to measure. One approach is to examine public discourse, using media content analysis and similar tools. Using Google NGrams Viewer (Michel et al. 2011), it is possible to assess the prominence of wind energy in public discourse over time. Figure 6 shows the frequency with which books published in English have used the phrase 'wind turbine'. The pattern from searches of media content in German and English-language newspapers (not shown here, for brevity) shows a smaller peak in 1980, and much more rapid growth since 2000 , but the overall pattern is similar. The implication from the 


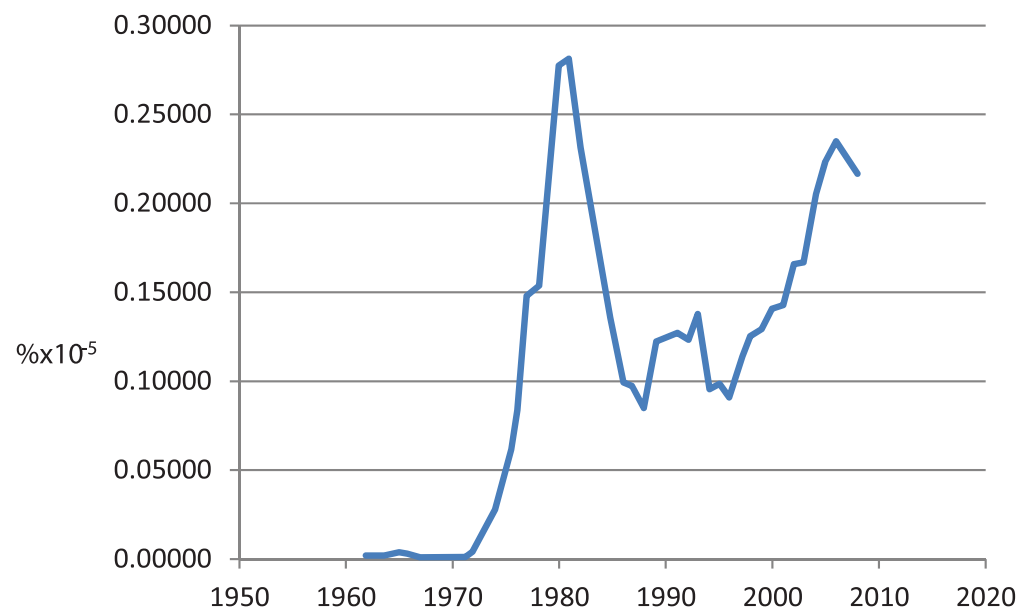

Figure 6. 'Wind Turbine' as a proportion of all 2-word phrases in all books published in English. Source: Google N-gram viewer.

figure is clear: wind turbines became a subject of interest during the early 1970s, likely in response to rising environmental concerns and the oil crisis. Interest waned during the 1980s, as concerns over energy fell, but interest has been increasing ever since, as environmental concerns have risen up the public agenda and the wind industry has grown.

Public statements and investments by major established firms are also clear indicators of positive expectations about the future of the technology. The entry of major firms such as Siemens (in 2004) and GE (in 2003), indicated that the sector had become seen as a mainstream part of the energy system.

\section{Associated policies}

In the formative phase, the most important policy events that influenced the direction of search were the initiation of R\&D programmes on wind energy. As discussed in earlier, the structure of R\&D programmes was often based on a presumed direction of search, focusing on multi-MW turbines. As it turned out, this assumed route to success was a major system weakness in all early $R \& D$ programmes. This was not simply a case of government 'getting it wrong', since most of the firms, experts and engineers involved agreed with the direction, which focused on science-intensive research on efficient, large and light-weight designs. Early success was generated by the Danish innovation system, not because government there chose better (Danish R\&D also targeted larger, more efficient turbines) but because government deployment support (in the form of investment subsidies and testing facilities) had not closed off the ability of small players to innovate with simpler designs. The difference in Denmark was the provision of a consistently supportive broader environment for wind energy in general, alongside specific R\&D investment in the designs that were (erroneously, it turned out) thought most likely to generate success. Supporting the broad portfolio of wind technologies and enabling a diversity of solutions within that portfolio was the key to Denmark's success. Systemic policy instruments such as roadmapping, foresight activities and collaborative priority-setting processes (including the IEA Wind implementing agreement) have also helped identify specific challenges that need to be overcome and direct activities towards overcoming them. 
In the growth stage, policy influence on the direction of search has rested on the ability of governments to create credible aspirations for the future development of wind power. Targets, technology roadmaps and climate policy commitments have all acted as incentives for actors to identify wind energy as an area for future industrial growth. Policy targets have been introduced and progressively strengthened in all the countries studied. Alongside targets, market support policies for wind energy are important in creating incentives for actors to join the system and strengthen the credibility of wind as a future industry. Subsidy policies, however, can reduce the urgency for cost reduction, leaving policymakers with a balancing act. On the one hand, policies that provide guaranteed markets for wind encourage new market entrants and thus enable system growth and learning; on the other, such policies reduce incentives for cost reduction. Early US policies, in the 1980s, have been seen as providing insufficient guidance towards quality and cost, whereas UK policies in the 1990s focused too much on cost reduction and so prevented experimentation and the entrance of new actors. Policies have been most successful where they have maintained incentives to invest in wind energy and join the industry, but have progressively increased incentives for cost reduction.

\section{Market formation}

Globally, the wind sector has become successful in creating markets (see Figure 7), though in global energy terms the contribution is small: wind supplies just over $1 \%$ of global electricity (Greenpeace and GWEC 2010). Further development of markets for wind is essential if it is to make a meaningful contribution to global emissions reductions.

Prior to 1990, most markets began as demonstration programmes and trials, or through the activities of enthusiasts (with the exception of the 1980s California wind boom).

The earliest markets for wind power were created during the formative phase, in Denmark and the USA, and later in Germany. Early-stage markets tended to rely on support for capital costs (such as capital grants) in addition to production incentives. Figure 8 shows installed capacity in the USA, Germany, UK and China, and shows early market development in the USA, the significance of Germany's market, the slow progress in the UK and the very rapid growth in China's market since 2005.

In all countries, markets have been volatile (Nemet 2010), as a result of the political dynamics of support for wind energy. This has been clearly the case in the USA, where on-again/off-again

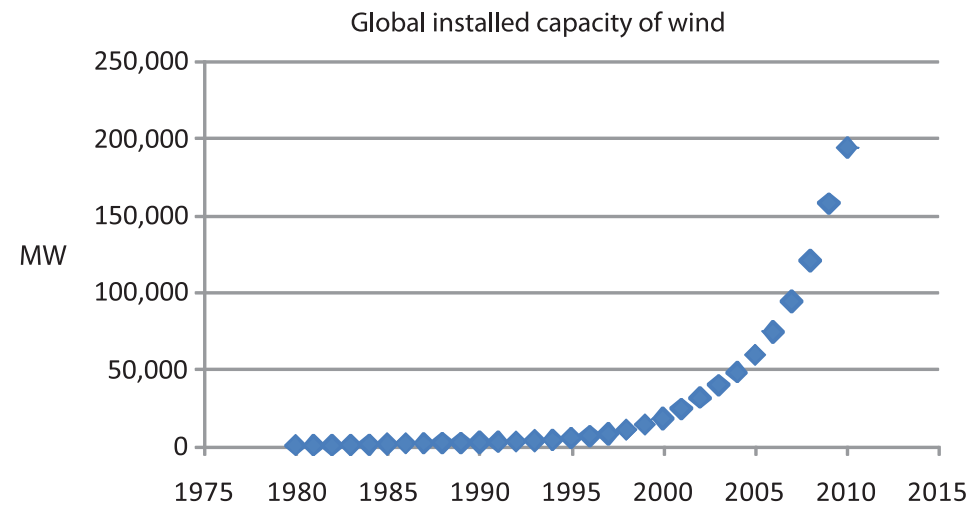

Figure 7. Global installed capacity of wind, in MW (GWEC 2011). 


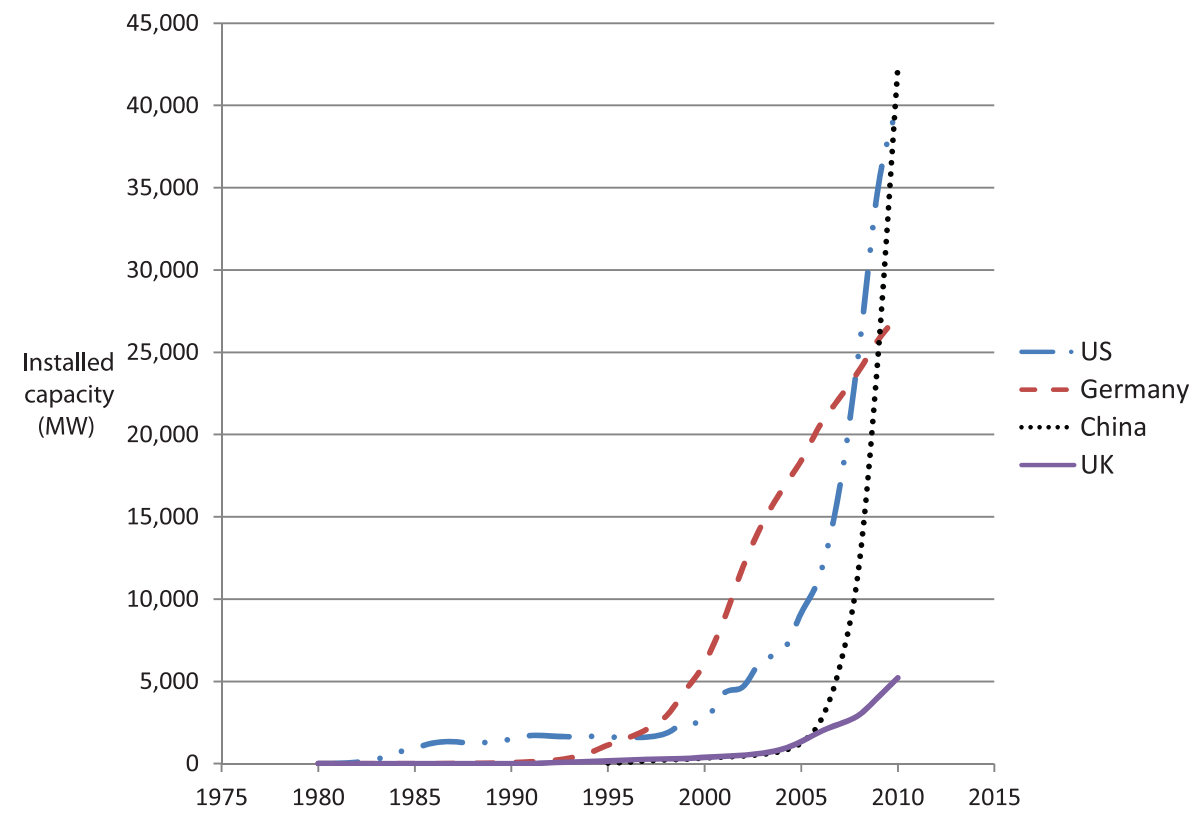

Figure 8. Wind installed capacity in the USA, Germany, China and UK (GWEC 2011).

support from the Production Tax Credit has been a result of political battles in Congress. The fact that there has been little international co-ordination of wind energy development and different national wind innovation systems have developed at different rates at different times, has meant that globally the industry has been able to develop more or less continuously, with a market downturn in one country being somewhat offset by a boom in another. Policy harmonisation might have led instead to a global bust in wind energy developments, with implications for industrial capacity, which is a critical element in determining feasible rates of diffusion (Kramer and Haigh 2009). As costs of wind energy have fallen and the consensus on climate change has hardened, policies in support of wind have become more stringent and more widespread, enabling more rapid growth.

\section{Associated policies}

Market formation has come about as a direct result of policy activity. All innovation systems require work to be done to enable the formation of markets - whether regulatory, political, cognitive, or symbolic work (Geels 2004). Low-carbon energy options in addition require a market to be created that reflects the value of reduced emissions.

In the formative phase, successful policies were those that enabled learning, such as Germany's 100/250 MW programme. The US Public Utility Regulatory Policies Act (PURPA) in 1978 and subsequent investment tax incentives, enabled very rapid market growth in California, but failed to provide incentives for quality installations and was short lived, resulting in a bust for the industry.

In the growth phase, successful policy instruments have been those that provided dedicated support for wind deployment (rather than general support across all renewable energy technologies). There is a large literature on the effectiveness of various policy instruments in developing markets for renewable energy, which suggests that policy mechanisms that provide greater investor confidence, such as feed-in tariffs, have tended to be more effective than those that expose investors to 
significant price risks (IEA 2008; Mitchell, Bauknecht, and Connor 2006; Ragwitz et al. 2007). For example, the UK has experienced much less growth in wind energy than Germany despite providing more policy support in terms of $\$ / \mathrm{kWh}$, because of exposure of investors to risk. Renewable energy targets have been cited as especially important in driving investment (Anon 2011). China's blend of policy instruments (concession bidding plus various feed-in arrangements and renewable portfolio standards) has become successful despite frequent changes in the form of policy support. In this case, changes in policy have not appeared to significantly weaken investor confidence, because of consistent and unambiguous political support from senior levels of the central government (particularly since 2005).

\section{Acquisition of legitimacy/overcoming resistance to change}

Like all new potentially disruptive technologies, wind power has had to establish legitimacy as a viable player within the energy system and overcome various sources of resistance. This process has had to occur in all energy markets, subject to different political, cultural, regulatory and economic contexts.

It is not straightforward to measure the extent to which wind energy is seen as a 'legitimate' power source within a given national energy system. Indeed, it is likely that the perceived legitimacy of a new technology is not stable but fragile, subject to ongoing negotiation between actors within the energy innovation system (Hendriks 2009). Hekkert et al. (2007) suggest that it may be possible to 'map' this function by mapping the establishment and rise of lobby groups and industry associations. The major European and American wind energy industry associations were founded in the late 1970s and during the 1980s, by networks of pioneers, researchers, engineers and enthusiasts. However, detailed data on membership and funding of such groups over time is not available.

The establishment of legitimacy also requires work to overcome active resistance to change. This resistance can be expressed through the political system (such as parliamentary debates and motions to remove or reduce support for wind energy); through the local planning system (which can be measured by wind farm approval rates over time); and through lobbying against wind energy by competing energy interests. In general, just as with legitimacy, resistance to a given technology is hard to measure with any objectivity, since the nature, intensity and manifestation of resistance is dynamic, multi-scale and variable between jurisdictions.

Several analysts have commented on the development of legitimacy within the innovation systems of the UK, Germany and the USA, and have suggested ways in which policy instruments have influenced legitimacy and resistance. They have argued:

(1) Structures of ownership were important in early phases. Early deployments in Denmark and Germany were often owned by local communities, farmers or cooperatives. In contrast, in the UK and the USA, initial deployments were owned by larger-scale corporate actors. These differences were the result of different structures of policy support. Several authors have argued that the involvement of local communities and a broader constituency of actors helped to embed early legitimacy of wind power in Denmark and Germany (Breukers and Wolsink 2007; Mendonça, Lacey, and F. Hvelplund 2009; Mitchell and Connor 2004).

(2) The establishment of a domestic wind industry has promoted legitimacy in host countries, because an emerging industry develops advocacy and lobbying activities. The emergent wind industry was important in Germany in political battles with utilities over support for wind in the 1990s (Jacobsson and Lauber 2006). 
(3) In contrast to this bottom-up story of early legitimacy emerging from Europe and the USA, our work suggests that legitimacy of wind in China has had a strong top-down component. In China, central government has promoted wind power nationally in response to key policy drivers (energy security, air and water pollution, and climate change), amid a generally increasing profile of environmental concerns within the Chinese bureaucracy since 2000.

(4) Early legitimacy in the USA was undermined by the poor quality of turbines erected during the California 'wind rush' in the early 1980s (Wallace 1995). This was partly because policy instruments supporting wind focused on support for capacity, not for production, which resulted in low incentives for high-quality turbines. Furthermore, the incentives were offered as tax credits, which meant that wind investments were seen by some as a tax scam for the wealthy (Garud and Karnøe 2003; Gipe 2003).

(5) Continued technological advancements have been important in enabling wind to become established. Lower costs, more reliable performance, and technological solutions to potential sources of resistance (such as reductions in noise) have been important in enabling legitimacy.

(6) External factors have been critically important. In the 1970s and 1980s, the oil crises and emerging environmental concerns led to government investments in wind R\&D. In Europe, acid rain and Chernobyl kept wind on the policy agenda during the late 1980s and early 1990s (Lauber and Mez 2004). In the USA, the fiscally conservative and free-market-oriented Reagan administration opposed support for wind, on the basis that the market should determine technology choices (Menz 2005).

As the wind innovation system has become increasingly successful, an additional source of legitimacy has become important. Wind energy has emerged as an important industry for global competitiveness, and wind policy has become seen as economic development policy. UK policies to support investments in offshore wind are explicitly framed as an opportunity for the UK to develop an export opportunity.

\section{Associated policies}

Policies that enabled the innovation system to enhance its broader democratic legitimacy were those that:

(1) Enabled broader stakeholder participation (through market and R\&D support mechanisms that enabled participation of entrepreneurs, communities and small businesses; and through democratic processes such as deliberative polling (e.g. Luskin, Fishkin, and Plane 1999);

(2) Enabled the establishment of an industry that could then form the nucleus of an advocacy coalition (again, market structures that prevent the emergence of dedicated companies - for example by delivering only on-again, off-again support - are less successful here);

(3) Ensured support volume was consistent with performance.

Policies have had a more direct role in overcoming specific forms of resistance to wind power, and there have been several key areas in which this has occurred:

(1) Standardisation and safety codes with respect to turbines. An important early-stage development was the establishment of recognised quality standards for wind turbines. This occurred in both Denmark and the USA during the formative period of the 1970s and 1980s, with 
government support for wind deployment restricted to turbines meeting basic quality specifications. International standardisation was then established through the IEA Wind programme. Standardisation was an important enabling step for a functioning market in the new technology.

(2) Connection rules and transmission access. Regulatory structures guaranteeing connection of renewables to the grid (such as the PURPA regulations introduced in 1978 in the USA) have been important in many countries, since established utilities have often been reluctant to connect new, unfamiliar and small-scale sources of power. Regulatory changes around who bears the cost of connection have also been key. More recently, the regulatory structures governing transmission upgrades and system balancing have become critical areas in which the wind industry has advocated regulatory change.

(3) Planning approvals. Wind farms, and associated transmission structures, are often major infrastructure projects, with implications for landscape, local environment, and local residents. Planning permission can be a major regulatory barrier and new regulatory structures around permissions have been key in promoting wind energy markets. Overcoming this form of resistance to change is closely related to the establishment of broad social legitimacy of the technology.

\section{Mobilisation of resources and financing}

Any emerging innovation system needs to attract three kinds of resources: Skilled human capital, financial capital and complementary assets such as network infrastructure (Bergek et al. 2008). Here we focus principally on indicators of financial resources. Public financial resources mobilised for wind energy R\&D were reported in an earlier subsection, and this subsection reports financial resources mobilised for deployment.

A crude estimate of overall wind energy investment can be obtained by multiplying annual capacity additions by an estimate of wind energy capital costs in that year. Figure 9 shows such an estimate of annual investment in wind energy in four countries from 1984 to 2007. Capital cost data are based on those in (Wiser and Bolinger 2009) for the USA, which correspond well to those from the UK provided by Junginger, Faaij, and Turkenburg (2005). The data demonstrate the scale of investment mobilised during the California wind boom of the 1980s. While the capacity additions during this period were relatively small (as illustrated previously in Figure 8), turbine technology was much more expensive than in later periods.

Pew Charitable Trusts (Anon 2011) reports that in 2010 US $\$ 95$ billion was invested by G-20 countries in the wind sector. China, the USA and the EU countries were easily the largest investors in wind energy in 2010.

\section{Associated policies}

Key policies stimulating this innovation system activity include many of those discussed previously, since R\&D funding policy and subsidies for market development constitute a direct policy-driven mobilisation of resources; meanwhile, policies that promote the legitimacy of wind energy and remove resistance to change reduce investment risks, facilitating private sector investment.

In the case of China, financing has also come from bilateral aid (during the formative phase) and more recently through global policy instruments including the Clean Development Mechanism. Lewis (2010) has assessed the importance of carbon finance in the Chinese wind sector, noting that the volume of clean development mechanism (CDM) finance is dwarfed by overall levels of investment in wind in China and is similar to the volume of money flowing to western countries in 


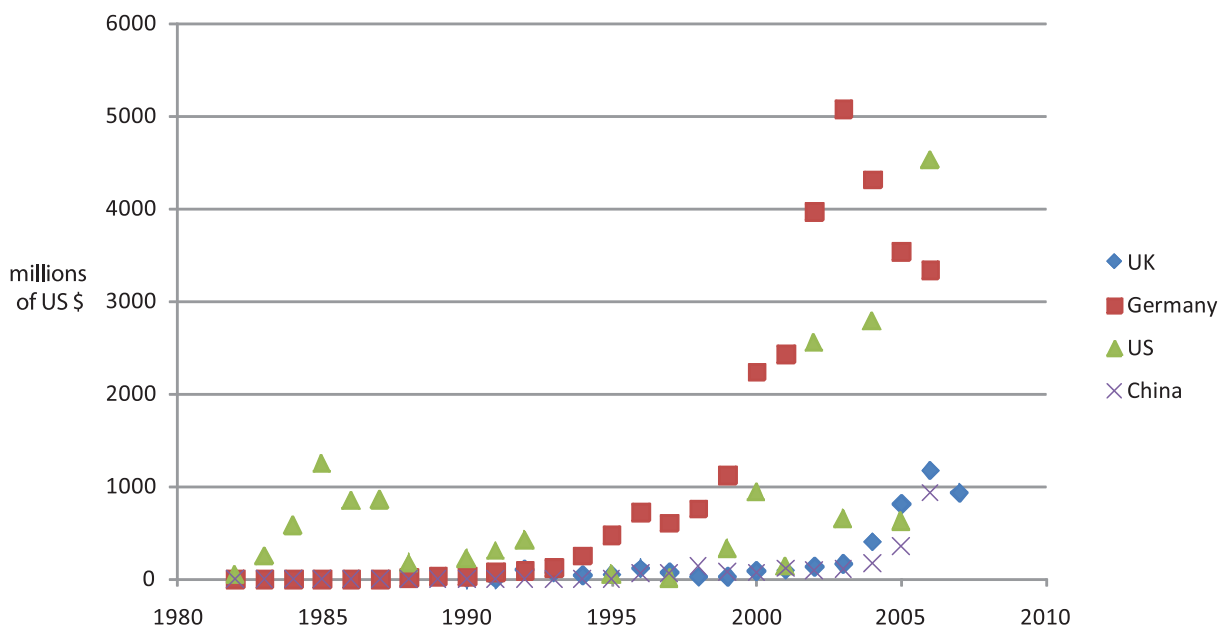

Figure 9. Crude estimates of total investment in wind energy installations in China, Germany, the UK and the US, 1984-2007. Calculated from wind capital cost data and deployment statistics. Note that the years since 2007 have seen strong increases in investment, particularly in China and the USA.

the form of patent licensing fees for turbines. The overwhelming majority of Chinese financing for wind power since 2006 has been provided by the major state-owned power corporations. CDM can be seen as having added to the financial resource available, and to the broader legitimacy of wind, but it has not been a major driver of deployment or of knowledge transfer (Lewis 2010).

\section{Conclusions}

\section{Formation, growth and expansion: wind energy in four regions}

The innovation system literature highlights the process of cumulative causation, by which feedbacks between innovation system activities enable growth. Here we summarise the outcomes of interactions of different activities and particular policies in each region.

- In Germany, early policy support enabled experimentation and learning with a diversity of options, and initial industry growth. The political dynamics were aided by external events (such as Chernobyl) and by the establishment of a domestic industry that lobbied for further support, which was critical when incumbent industries threatened the policy support structure. The dedicated feed-in tariff has reduced investor risk and enabled growth in the domestic market. The success of German wind firms has enabled Germany to become an exporter of wind technologies and intellectual property, which has been important in maintaining the political strength to lobby for continued support.

- In the USA, early policy enthusiasm led to a boom of poor quality turbines, followed by a collapse in legitimacy and a bust. Only after the successful developments of wind energy in Europe did governments have the confidence to provide strong support to wind. State policies in particular have driven the development of the industry, principally through renewable portfolio standards. 
- In the UK, early deployment policy was unhelpful for the establishment of a UK-based innovation system, because it focused too heavily on cost reduction, and not enough on enabling experimentation and market entry by new actors. As a result, a domestic turbine manufacturing industry has never emerged. Later policy support provided a more stable environment, but still within a framework that exposed investors to significant risk, leading to higher overall costs. Disappointing market growth has led to increasingly complex policy arrangements that in effect provide dedicated support for wind, similar to a feed-in tariff. Higher barriers to wind power in the planning approvals process have been, by some authors (e.g. Toke, Breukers, and Wolsink 2008), blamed on policy support structures that inhibit community benefit and participation in wind energy investment.

- In China, the success of wind energy is better explained as an outcome of Chinese central government policy than as a result of international technology transfer measures such as the CDM or bilateral donor programmes. The key feature in China has been the establishment of the legitimacy of wind as an important technology in China's central government, coupled with global networking that has enabled knowledge acquisition by Chinese firms. The process of legitimation has been facilitated by international policy mechanisms (such as CDM), by international experience, and by China's broader energy policy context. International policy instruments have thus been more effective as enablers of endogenous growth of a Chinese wind innovation system than as direct drivers of technology adoption in China. Despite changing policy support mechanisms, strong policy support from central government and explicit commitments to create a domestic industry have generated sufficient investor confidence to drive rapid market growth. Protectionist policies have been key to the success of China in nurturing a domestic industry, which has enabled cost reductions and facilitated market growth.

\section{Technology policies in a globalised world}

Wind energy has been subject to a number of global technology policy initiatives (similar to those discussed in De Coninck et al. (2008)), including those focusing on R\&D collaboration (e.g. IEA Wind) and financing (CDM), but these appear to have been less important than national level policies in driving technology development and transfer. This conclusion focuses attention on the policy frameworks that national governments use to not only develop new technologies, but also to acquire and deploy the leading technologies developed by others.

The TIS approach has historically been used to focus on developments within countries and cross-country comparative studies have examined only the early stages of the innovation system. In this analysis, we have extended the innovation system perspective to the stage at which mature technologies are adopted and diffused across borders into new institutional, economic and political contexts. This is a crucial process in global low-carbon technology policy and one that has received relatively little attention from innovation system scholars. Our work suggests that system failures may pervade this transfer process, just as they do the process of development and establishment of new technologies.

China's innovation system for wind energy went through a process of system-building, but with dynamics rather different from those of countries in which wind technologies were first developed. With a mature technology, the core technological challenges have been overcome and innovation system activities change in nature (e.g. original knowledge development is less important than knowledge acquisition), but systemic problems such as the establishment of legitimacy remain. We therefore suggest that the extension of the TIS framework to the transfer of mature technologies is likely to be a fruitful area for research. 


\section{Conclusions from the systemic perspective}

Policy recommendations for low-carbon innovation generally advocate a mix of implicit or explicit carbon prices (creating 'market-pull'), and $R \& D$ funding (enabling technology-push). This perspective neglects the institutional and political dynamics of supporting new technologies. The most important policy conclusion of the present analysis is that significant political and institutional work must go alongside attempts to provide price support and R\&D funding and that the structures through which price supports and R\&D funding are organised affect the dynamics of the innovation system. In addition to market failures the dynamics of the innovation system are strongly shaped by institutional and system coordination failures. Put another way, the market structures and institutional frameworks in which technologies compete, and the way in which R\&D funding is used to support experimental deployments, can be as important in enabling development and deployment of new technologies as the actual prices or levels of funding overall. In summary, the institutional context of policy is as important as the actual policy. Systemic policy instruments (Smits and Kuhlmann 2004), which aim to address system failures, can be important alongside traditional R\&D and deployment policies.

Our research shows that the wind innovation system has progressed through different stages, from early formative stages when the technology was initially being developed, through to the current global market. Policy instruments that were successful in supporting deployment and further innovation in later stages were not necessarily successful in earlier periods. Both 'market pull' and 'technology push' policies are important throughout, but the necessary structure of policy supports and the institutional frameworks through which they are delivered change along with the challenges faced by the emerging system. Policy-makers have to be engaged and adaptive throughout.

Public R\&D funding, and support for testing and standards-setting, was critical to enable the initial development of the technologies; learning through publicly funded experimental deployment was important in subsequent stages. Initial deployments were most successful where they explicitly targeted and enabled learning and technological improvements, rather than those that focused on deployments of least-cost technologies. How different national systems have managed this trade-off between short-term efficiency and medium to long-term learning-oriented deployment of low-carbon technologies can explain differences between them in terms of effectiveness of public support. The challenge is how to establish an institutional framework that can resolve this trade-off: in essence, the challenge is to establish balance between 'strategising' and 'economising' principles.

Establishing and maintaining a supportive environment for the development and deployment of new technologies is also a long-term political process that often goes against the short-term interests of powerful incumbent industries. This makes it impossible for governments to maintain policy certainty for low-carbon innovation, since powerful lobbies will seek opportunities to change policies; yet a lack of policy certainty is a major barrier to the deployment of new technologies. Governments can help to overcome this process by encouraging new entrants, whose interests are dependent on the success of the low-carbon innovation system, and who will form the nucleus of an advocacy coalition for its defence.

\section{Acknowledgements}

This paper was prepared as part of the UCL Grand Challenge on Carbon Governance. Additional support came from the UK Engineering and Physical Sciences Research Council, through the UK Sustainable Hydrogen Energy Consortium 'plus' workstream. 


\section{Note}

1. PCT, or Patent Cooperation Treaty patents, are a special kind of patent that is registered with the World Intellectual Property Office and establish an option to claim patent priority on the invention within any PCT signatory nation. They are a useful indicator for global trends.

\section{Notes on contributors}

Will McDowall is a Research Associate at the UCL Energy Institute. He has previously worked in research and policy advisory roles in government, NGOs and academia in Canada and the UK. His current research focuses on the governance of innovation, appraisal of long-term energy futures and in the use of evidence in climate and energy policy-making.

Paul Ekins is an environmental economist and is Professor of Energy and Environment Policy at the UCL Energy Institute, University College London. He is a Co-Director of the UK Energy Research Centre, in charge of its Energy Systems theme and also leads UCL's involvement in large research consortia on Bioenergy and Hydrogen. He was a Member of the Royal Commission on Environmental Pollution from 2002 to 2008 and also has extensive experience consulting for business, government and international organisations. Paul Ekins' academic work focuses on the conditions and policies for achieving an environmentally sustainable economy.

Slavo Radošević is Professor of Industry and Innovation Studies at University College London and deputy director of the School of Slavonic and East European Studies (SSEES). His research interests are in the area of science, technology, industrial change and foreign direct investments in countries of central and eastern Europe and he continues to be involved in international projects in this area. He has published extensively in international journals on issues of innovation policy and innovation in CEE and has edited several books in this area. He is acting as an expert for the various DGs of the European Commission, as consultant to UNESCO, OECD, UN ECE, UNIDO, World Bank and Asian Development Bank as well as to several CEE governments. He is member of the Management Committee of the ERAWatch network.

Le-Yin Zhang is a senior lecturer and director of MSc in Urban Economic Development in the Development Planning Unit, University College London. She has many years of professional experiences, including numerous consultancy assignments for local, national and international organisations. Her research interests range from the management of urban economies, the linkages between climate change and sustainable development in developing countries and cities, to the effects of Chinese policy reforms on economic development at home. China's response to climate change represents the latest in a string of significant development issues that she has studied relating to China.

\section{References}

Andersson, T. 1998. Managing a systems approach to technology and innovation policy. OECD STI Review, no. 22: 9-30. Anon. 2011. Who's winning the clean energy race? 2010 ed. Washington, DC: Pew Charitable Trusts.

Bergek, A., S. Jacobsson, B. Carlsson, S. Lindmark, and A. Rickne. 2008. Analyzing the functional dynamics of technological innovation systems: A scheme of analysis. Research Policy 37: 407-29.

Breukers, S., and M. Wolsink. 2007. Wind power implementation in changing institutional landscapes: An international comparison. Energy Policy 35: 2737-50.

Coenen, L., and F.J. Díaz López. 2010. Comparing systems approaches to innovation and technological change for sustainable and competitive economies: An explorative study into conceptual commonalities, differences and complementarities. Journal of Cleaner Production 18: 1149-60.

De Coninck, H., C. Fischer, R.G. Newell, and T. Ueno. 2008. International technology-oriented agreements to address climate change. Energy Policy 36, no. 1: 335-56.

Edquist, C. 2001. The systems of innovation approach and innovation policy: An account of the state of the art. Paper presented at the DRUID Conference, June 12-15, 2001, in Aalborg, Denmark.

Fouquet, R. 2010. The slow search for solutions: Lessons from historical energy transitions by sector and service. Energy Policy 38: 6586-96.

Freeman, C. 1987. Technology policy and economic performance: Lessons from Japan. London: Pinter.

Garud, R., and P. Karnøe. 2003. Bricolage versus breakthrough: Distributed and embedded agency in technology entrepreneurship. Research Policy 32: 277-300.

Geels, F.W. 2002. Technological transitions as evolutionary reconfiguration processes: A multi-level perspective and a case-study. Research Policy 31: 1257-74. 


\section{W. McDowall et al.}

Geels, F.W. 2004. From sectoral systems of innovation to socio-technical systems: Insights about dynamics and change from sociology and institutional theory. Research Policy 33: 897-920.

Gipe, P. 1994. Overview of worldwide wind generation. Renewable Energy 5, no. 1-4: 542-50.

Gipe, P. 2003. Why I oppose the production tax credit. Available at www.wind-works.org (accessed October 3, 2011).

Greenpeace and GWEC. 2010. Global wind energy outlook 2010. Amsterdam/Brussels: Greenpeace and the Global Wind Energy Council.

Grübler, A., N. Nakicenovic, and D.G. Victor. 1999. Dynamics of energy technologies and global change. Energy Policy 27: $247-80$.

GWEC. 2011. Global wind statistics 2010. Brussels: Global Wind Energy Council.

Harborne, P. and C. Hendry. 2009. Pathways to commercial wind power in the US, Europe and Japan: The role of demonstration projects and field trials in the innovation process. Energy Policy 37: 3580-95.

Hekkert, M.P., R.A.A. Suurs, S.O. Negro, S. Kuhlmann, and R.E.H.M. Smits. 2007. Functions of innovation systems: A new approach for analysing technological change. Technological Forecasting and Social Change 74: 413-32.

Hendriks, C. 2009. Securing public legitimacy for long-term energy reforms. Paper presented at the Public Policy Network Conference, in Australian National University, Canberra.

Hennessy, D.A., J. Roosen, and H.H. Jensen. 2003. Systemic failure in the provision of safe food. Food Policy 28, no. 1: 77-96.

Heymann, M. 1998. Signs of hubris: The shaping of wind technology styles in Germany, Denmark, and the United States, 1940-1990. Technology and Culture 39: 641-70.

IEA. 2001. IEA wind energy annual report 2000. National Renewable Energy Laboratory, Golden, Colorado: International Energy Agency Executive Committee for the Implementing Agreement for Co-operation in the Research and Development of Wind Turbine Systems.

IEA. 2008. Deploying renewables: Principles of effective policy. Paris: IEA/OECD.

IEA. 2011. RD\&D statistics. Paris: International Energy Agency.

Jacobsson, S., and A. Johnson. 2000. The diffusion of renewable energy technology: An analytical framework and key issues for research. Energy Policy 28: 625-40.

Jacobsson, S., and V. Lauber. 2006. The politics and policy of energy system transformation - explaining the German diffusion of renewable energy technology. Energy Policy 34: 256-76.

Junginger, M., A. Faaij, and W.C. Turkenburg. 2005. Global experience curves for wind farms. Energy Policy 33: $133-50$.

Kemp, R., J. Schot, and R. Hoogma. 1998. Regime shifts to sustainability through processes of niche formation: The approach of strategic niche management. Technology Analysis \& Strategic Management 10: 175-95.

Klaassen, G., A. Miketa, K. Larsen, and T. Sundqvist. 2005. The impact of R\&D on innovation for wind energy in Denmark, Germany and the United Kingdom. Ecological Economics 54: 227-40.

Kramer, G.J., and M. Haigh. 2009. No quick switch to low-carbon energy. Nature 462, no. 7273: 568-69.

Lauber, V., and L. Mez. 2004. Three decades of renewable electricity policies in Germany. Energy \& Environment 15: 599-623.

Lee, B., I. Iliev, and F. Preston. 2010. Who owns our low carbon future? Intellectual property and energy technologies. London: Chatham House.

Lewis, J.I. 2007. Technology acquisition and innovation in the developing world: Wind turbine development in China and India. Studies in Comparative International Development 42: 208-32.

Lewis, J.I. 2010. The evolving role of carbon finance in promoting renewable energy development in china. Energy Policy 38: $2875-86$.

Lewis, J.I., and R. Wiser. 2007. Fostering a renewable technology industry: An international comparison of wind industry policy support mechanisms. Energy Policy 35: 1844-57.

Li, J., P. Shi, and H. Gao. 2010. China wind power outlook (Zhongguo fengdian fazhan baogao). Beijing: Chinese Renewable Energy Industries Association, Global Wind Energy Council, Greenpeace.

Luskin, R.C., J.S. Fishkin, and D.L. Plane. 1999. Deliberative polling and policy outcomes: Electric utility issues in Texas. Paper presented at the Annual Meeting of the Association for Public Policy Analysis and Management, November 4-7, 1999, in Washington, DC.

Matsuoka, K. 2005. Development of wind power technology in Japan. Ryukoku Journal of Economic Studies 44: 79-101.

Mendonça, M., S. Lacey, and F. Hvelplund. 2009. Stability, participation and transparency in renewable energy policy: Lessons from Denmark and the United States. Policy and Society 27: 379-98.

Menz, F.C. 2005. Green electricity policies in the United States: Case study. Energy Policy 33, no. 18: $2398-410$.

Metcalfe, J.S. 1994. Evolutionary economics and technology policy. Economic Journal 104, no. 425: 931-44.

Metcalfe, J.S. 1995. Technology systems and technology policy in an evolutionary framework. Cambridge Journal of Economics 19: 25-46. 
Michel, J.-B., Y.K. Shen, A.P. Aiden, A. Veres, M.K. Gray, T.G.B. Team, J.P. Pickett et al. 2011. Quantitative analysis of culture using millions of digitized books. Science 331, no. 6014: 176-82.

Mitchell, C., and P. Connor. 2004. Renewable energy policy in the UK 1990-2003. Energy Policy 32: 1935-47.

Mitchell, C., D. Bauknecht, and P.M. Connor. 2006. Effectiveness through risk reduction: A comparison of the renewable obligation in England and Wales and the feed-in system in Germany. Energy Policy 34: 297-305.

MOST. 2011. Science and technology programmes. Beijing: Ministry of Science and Technology.

Nemet, G.F. 2009. Demand-pull, technology-push, and government-led incentives for non-incremental technical change. Research Policy 38: 700-09.

Nemet, G.F. 2010. Robust incentives and the design of a climate change governance regime. Energy Policy 38: $7216-25$.

Peneder, M. 2008. The problem of private under-investment in innovation: A policy mind map. Technovation 28: 518-30.

Popp, D. 2010. Innovation and climate policy. Annual Review of Resource Economics 2, no. 1: 275-98.

Ragwitz, M., A. Held, G. Resch, T. Faber, R. Haas, C. Huber, R. Coenraads et al. 2007. Assessment and optimisation of renewable energy support schemes in the European electricity market. Brussels: Intelligent Energy, European Commission.

Smits, R., and S. Kuhlmann. 2004. The rise of systemic instruments in innovation policy. International Journal of Foresight and Innovation Policy 1: 4-32.

Stern, N. 2007. The economics of climate change: The Stern review. Cambridge: Cambridge University Press.

Taylor, M., D. Thornton, G. Nemet, and M. Colvin. 2006. Government actions and innovation in environmental technology for power production: The cases of selective catalytic reduction and wind power in California. Report for the California Energy Commission, University of California, Berkeley.

Toke, D., S. Breukers, and M. Wolsink. 2008. Wind power deployment outcomes: How can we account for the differences? Renewable and Sustainable Energy Reviews 12: 1129-47.

UNEP, EPO, and ICSTD. 2010. Patents and clean energy: Bridging the gap between evidence and policy. Brussels: United Nations Environment Programme, European Patent Office, and the International Centre for Trade and Sustainable Development.

Wallace, D. 1995. Environmental policy and industrial innovation: Strategies in Europe, the US and Japan. London: Royal Institute of International Affairs/Earthscan

WIPO. 2010. Patent-based technology analysis report-alternative energy technology. Geneva: World Intellectual Property Office.

WIPO. 2011. Patentscope database of PCT patents. Geneva: World Intellectual Property Organization.

Wiser, R., and M. Bolinger. 2009. 2008 wind technologies market report. Washington DC: Office of Energy Efficiency and Renewable Energy, US Department of Energy.

Woolthuis, R.K., M. Lankhuizen, and V. Gilsing. 2005. A system failure framework for innovation policy design. Technovation 25: 609-19. 
